\title{
Abrogation of growth hormone secretion rescues fatty liver in mice with hepatocyte- specific deletion of JAK2
}

\author{
Brandon C. Sos, ${ }^{1}$ Charles Harris, ${ }^{2,3,4}$ Sarah M. Nordstrom,, Jennifer L. Tran, ${ }^{1}$ \\ Mercedesz Balázs, 5 Patrick Caplazi,6 Maria Febbraio,7 Milana A.B. Applegate,7 \\ Kay-Uwe Wagner, ${ }^{8}$ and Ethan J. Weiss ${ }^{1,2}$ \\ ${ }^{1}$ Cardiovascular Research Institute, ${ }^{2}$ The Liver Center, and ${ }^{3}$ Division of Endocrinology, UCSF, San Francisco, California, USA. \\ ${ }^{4}$ The Gladstone Institute of Cardiovascular Diseases, San Francisco, California, USA. ${ }^{5}$ Department of Immunology, and ${ }^{6}$ Department of Pathology, Genentech, \\ South San Francisco, California, USA. ${ }^{7}$ Cell Biology Department, Lerner Research Institute, Cleveland Clinic, Cleveland, Ohio, USA. \\ ${ }^{8}$ Eppley Institute for Research in Cancer and Allied Diseases, University of Nebraska Medical Center, Omaha, Nebraska, USA.
}

\begin{abstract}
Non-alcoholic fatty liver disease is associated with multiple comorbid conditions, including diabetes, obesity, infection, and malnutrition. Mice with hepatocyte-specific disruption of growth hormone (GH) signaling develop fatty liver (FL), although the precise mechanism underlying this finding remains unknown. Because GH signals through JAK2, we developed mice bearing hepatocyte-specific deletion of JAK2 (referred to herein as JAK2L mice). These mice were lean, but displayed markedly elevated levels of GH, liver triglycerides (TGs), and plasma FFAs. Because GH is known to promote lipolysis, we crossed GH-deficient little mice to JAK2L mice, and this rescued the FL phenotype. Expression of the fatty acid transporter CD36 was dramatically increased in livers of JAK2L mice, as was expression of Pparg. Since GH signaling represses PPAR $\gamma$ expression and $C d 36$ is a known transcriptional target of PPAR $\gamma$, we treated JAK2L mice with the PPAR $\gamma$-specific antagonist GW9662. This resulted in reduced expression of liver $C d 36$ and decreased liver TG content. These results provide a mechanism for the FL observed in mice with liver-specific disruption in GH signaling and suggest that the development of FL depends on both GH-dependent increases in plasma FFA and increased hepatic uptake of FFA, likely mediated by increased expression of CD36.
\end{abstract}

\section{Introduction}

Non-alcoholic fatty liver disease (NAFLD) is increasingly common, with a worldwide prevalence of up to $25 \%$ (1). Known risk factors include conditions such as obesity and type 2 diabetes mellitus, starvation, malnutrition, drugs, inborn errors of metabolism, or infection (1). The pathogenesis is not well understood. Disorders of fatty acid oxidation, increases in fat synthesis, decreased triglyceride (TG) secretion, or abnormalities of leptin metabolism can predispose (2-7).

Recent evidence points to cytokine signaling and inflammation as important in the development of NAFLD in part through NF- $\kappa \mathrm{B}(8)$. TNF- $\alpha$ is increased in FLD in mice and is implicated in human disease (9-11). Mice deficient in IL-6 are predisposed to alcohol-induced FLD $(12,13)$. Mice with hepatocyte-specific deletion of the well-known transducer of cytokine signaling STAT5 were shown to develop fatty liver (FL) (14). Additionally, mice with FL show significant upregulation of SOCS proteins, and conversely, overexpression of SOCS1 and SOCS3 results in insulin resistance and FL $(15,16)$.

Growth hormone $(\mathrm{GH})$ is a pleiotropic hormone synthesized and secreted by the anterior pituitary gland $(17,18)$. GH signals through a type I cytokine receptor, the GH receptor (GHR) (19). Activated GHR recruits JAK2, which recruits and activates STAT factor family members (20-22). There are now at least 7 STAT family mem-

Authorship note: Brandon C. Sos and Charles Harris contributed equally to this work.

Conflict of interest: The authors have declared that no conflict of interest exists. Citation for this article: J Clin Invest. 2011;121(4):1412-1423. doi:10.1172/JCI42894 bers, including the highly homologous STAT5A and -B. Activated STAT5 translocates to the nucleus, where it effects transcription of target genes including insulin growth factor 1 (IGF1) (23). Mice deficient in GHR are GH insensitive, with decreased IGF-1 and a rise in circulating $\mathrm{GH}$ closely mimicking the human Laron syndrome (24). Mice with an N-terminal truncation of STAT5A and -B are also GH insensitive and have increased serum GH (25). Hepatocyte-specific deletion of STAT5A and -B causes a similar profile (26). This is not surprising, since plasma IGF-1 is derived predominantly from the liver and since liver-specific deletion of IGF-1 also causes a significant increase in serum GH concentration due to the loss of feedback inhibition $(27,28)$. Liver-specific IGF-1-deficient (LID) mice are insulin resistant but do not have FL (29).

Recently, mice with liver-specific deletion of GHR were shown to develop FL (30). This points strongly to the loss of GH signaling as mediating some or all of the FL phenotype in mice with liver-specific deletion of STAT5. However, there is contradictory evidence as to the role of GH in FL $(31,32)$. FL has not been described in any of the mouse models of GH excess or deficiency (24, 33-37). Interestingly, neither global disruption of GHR nor the N-terminal truncation of STAT5A and -B leads to FL $(24,25)$.

JAK2 is known to transduce intracellular signaling downstream of numerous cytokine and other receptors in the liver, including GH and IL-6 $(38,39)$. Mice with global deletion of JAK2 die at midgestation from defective erythropoiesis (40-42). A conditional JAK2 allele has been generated, but there are no published reports of mice with liver-specific deletion of JAK2 (42).

Here, we report the first description to our knowledge of mice with hepatocyte-specific deletion of JAK2 (JAK2L mice). Adult 

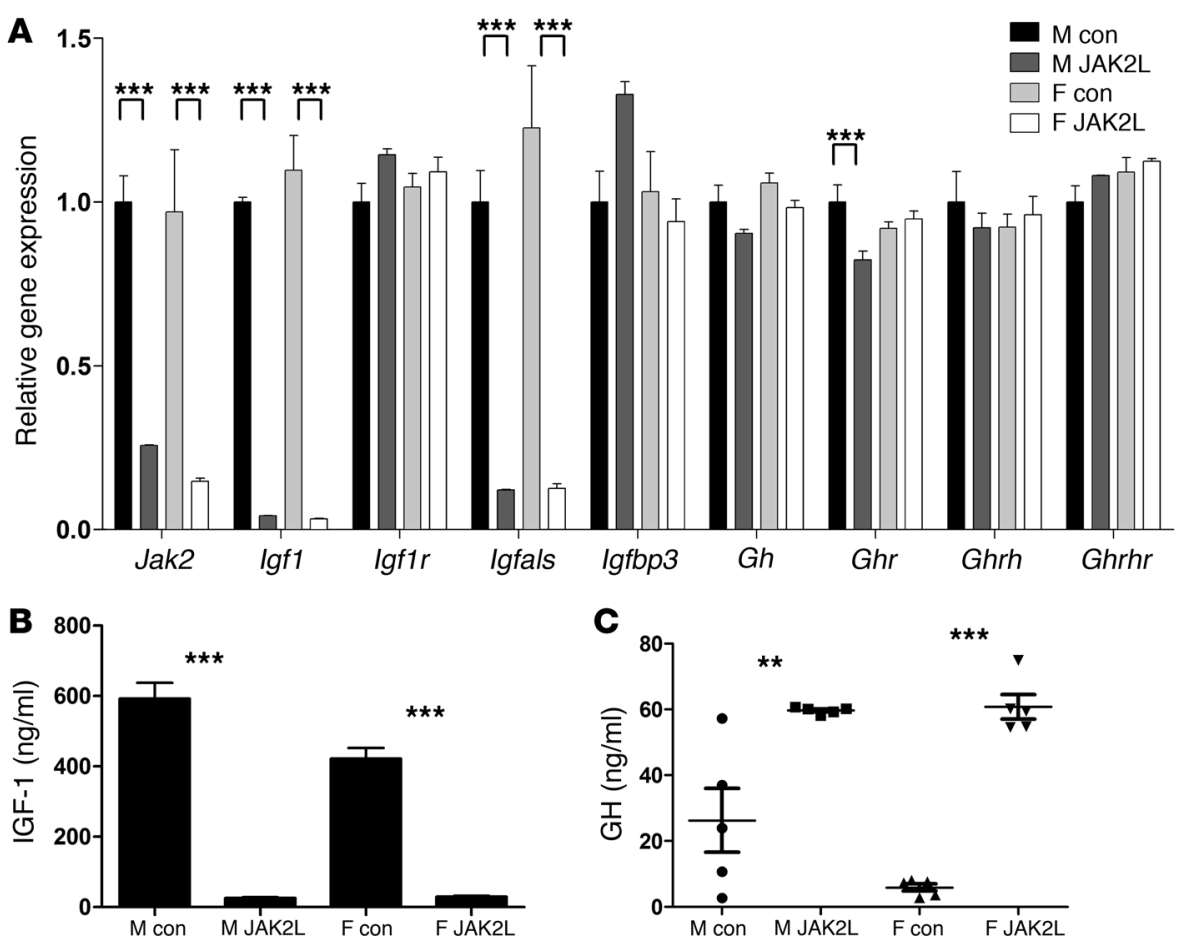

\section{Figure 1}

Effect of hepatocyte-specific deletion of JAK2 (JAK2L) on the GH signaling pathway and on body weight. (A) Relative expression of Jak2 and related genes in male (M) and female (F) JAK2L and control (Con) adult mice. Values are expressed as mean \pm SEM and normalized to male control levels ( $n=5$ for each group). (B) Serum concentrations of IGF-1 in male and female JAK2L and control mice $(n=5$ for each group). (C) Serum concentrations of GH in male and female JAK2L and control mice ( $n=5$ for each group). (D) Weight in grams of a cohort of male and female JAK2L and control mice over time in days ( $n=8-10$ for each time point). All values are expressed as mean \pm SEM; ${ }^{* *} P<0.01,{ }^{* * *} P<0.001$.
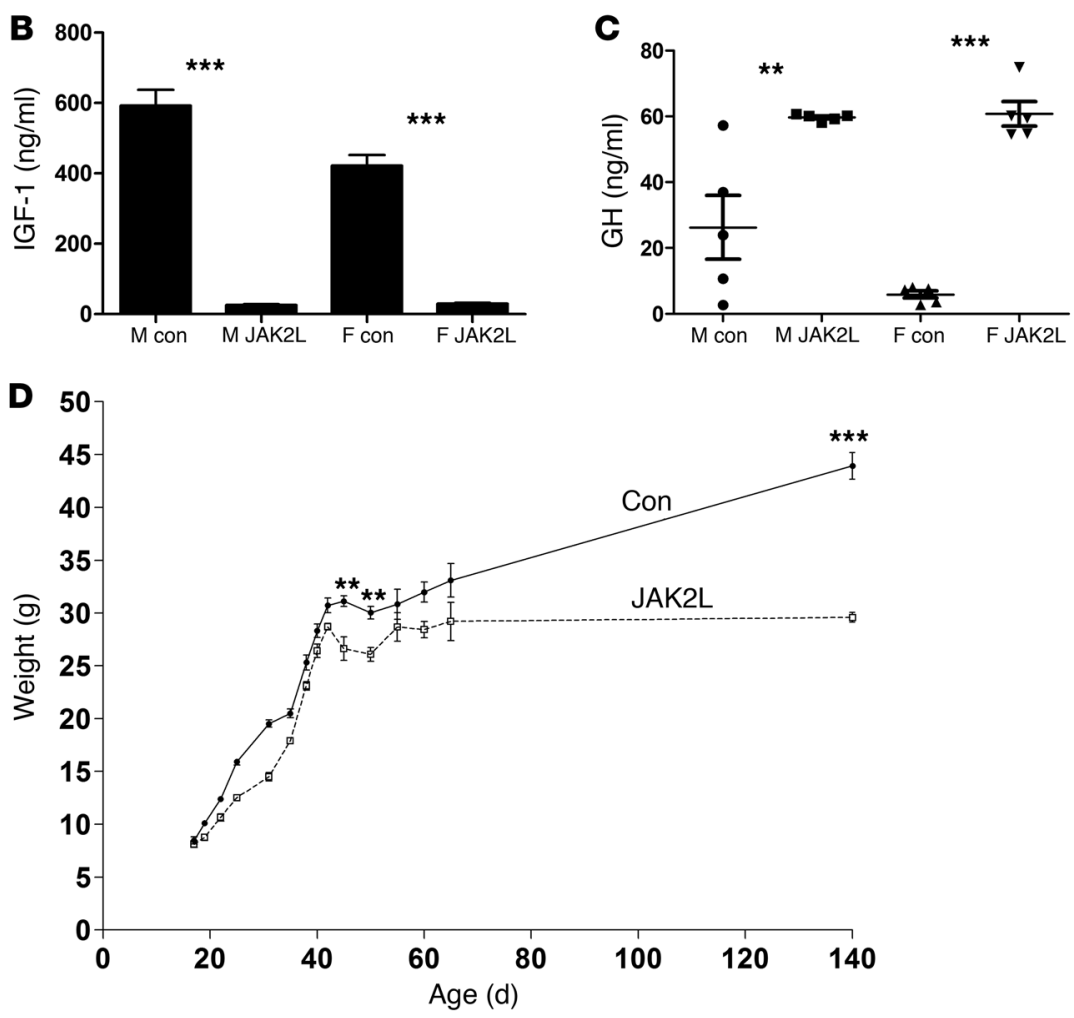

JAK2L mice had a near absence of circulating IGF-1; they were smaller and had a dramatic increase in serum GH levels. The livers were profoundly steatotic, with a 20 -fold increase in liver TG. There was no increase in fatty acid synthesis, nor was there a defect in TG secretion from the liver. JAK2L mice also had a significant reduction in body fat and had increased levels of serum FFAs. $\mathrm{GH}$ is known to stimulate lipolysis, and mice with disrupted GH signaling have increased adiposity $(43,44)$. Therefore, to determine whether dysregulated GH secretion might account for the FL phenotype via increased lipolysis and concomitant increase in serum FFA, we crossed JAK2L mice with GH-deficient little mice and found that loss of circulating GH completely rescued the FL phenotype. Furthermore, expression of fatty acid translocase (FAT, or CD36) was significantly increased. Since GH is known to inhibit PPAR $\gamma$ and since CD36 is a known transcriptional target of PPAR $\gamma$ $(45,46)$, we treated JAK2L mice with the PPAR $\gamma$-specific antagonist
GW9662 and found that the FL phenotype was largely reduced. Overall, this work explains the paradox of FL in mice with hepatocyte-specific, but not global, disruption of GH signaling. Further, the work has important implications regarding the hepatic lipid flux and mechanisms of FLD.

\section{Results}

Hepatocyte-specific deletion of JAK2 results in GH resistance in the liver. Mice with hepatocyte-specific deletion of both Jak2 alleles (JAK2L mice) were viable and had no obvious gross abnormalities as compared with littermate controls at birth. We isolated total RNA from the livers of individual 8-week-old mice and synthesized cDNA. From this, we measured gene expression using specific TaqMan primer probe sets individually generated and validated for each gene. Expression of Jak2 in the liver was reduced by $74 \%$ in male JAK2L mice versus controls $(P<0.001$; Figure $1 \mathrm{~A})$. This 

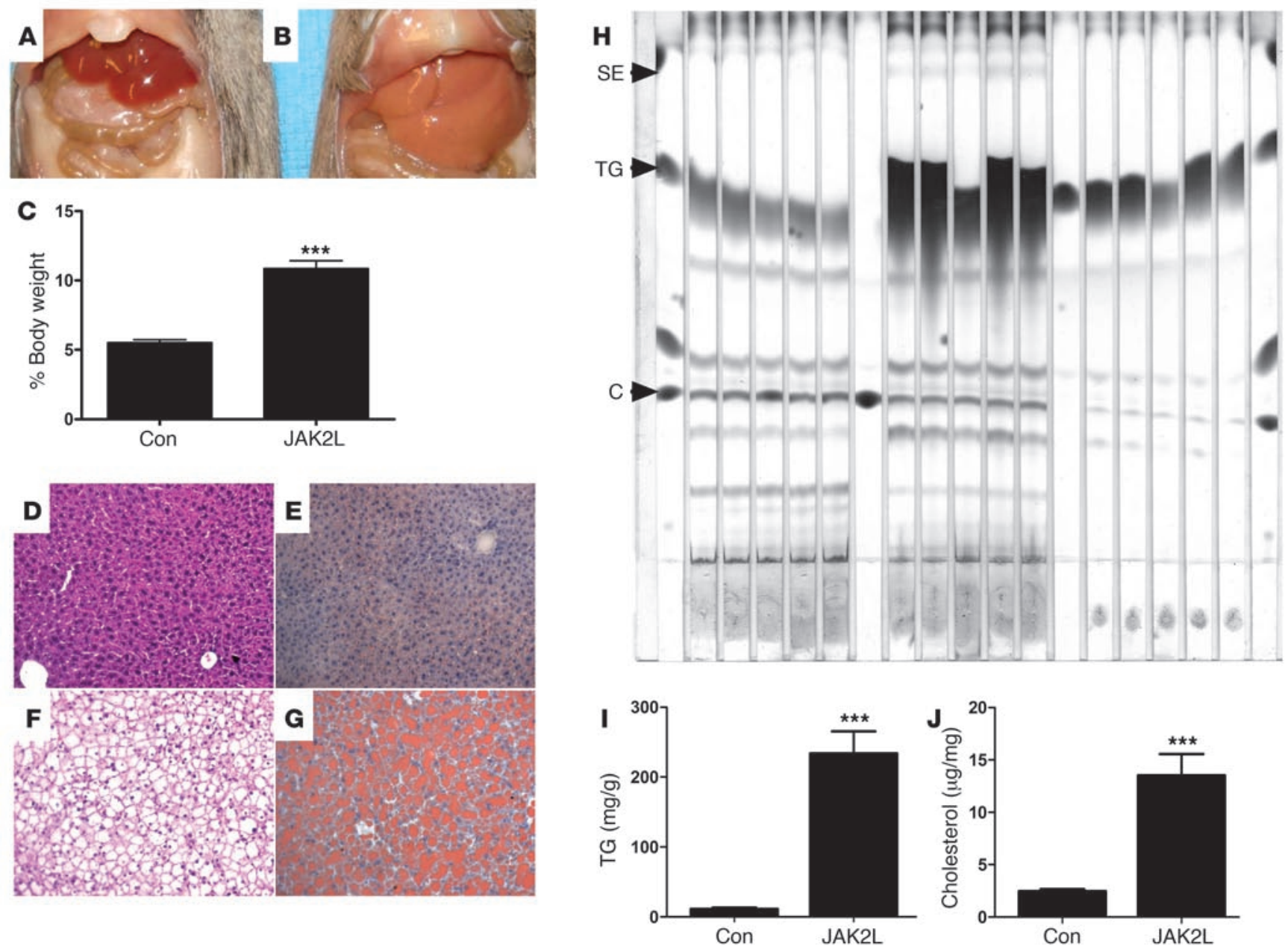

Figure 2

Hepatic steatosis develops in adult JAK2L mice. (A) Normal appearance of the liver of an 8-week-old control mouse. (B) Representative gross appearance of steatotic liver of an 8-week-old JAK2L mouse. (C) Liver weight normalized to body weight is expressed as percent body weight in control and JAK2L mice ( $n=5$ for each group). (D-G) Images of mouse liver taken using a Nikon Optiphot microscope at $\times 20$ magnification with a Zeiss Axiocam HRc camera. (D) H\&E-stained section of control liver. (E) Oil red O-stained section of control liver. (F) H\&E-stained section of JAK2L liver. (G) Oil red O-stained section of JAK2L liver. (H) TLC analysis of individual liver extracts of control (lanes 2-6), JAK2L (lanes 8-12), and a 1:10 dilution of JAK2L (lanes 14-18) samples. Premixed sterol esters (SE), TGs, and cholesterol (C) standards are all labeled on the left and were run in the first and last lanes. (I) Quantity of TG in liver extracts from control and JAK2L mice ( $n=5$ for each group). (J) Quantity of cholesterol (total and sterol esters) in liver extracts from control and JAK2L mice ( $n=5$ for each group). Male mice were used exclusively in the experiments in this figure. All values are expressed as mean \pm SEM. ${ }^{* * *} P<0.001$.

is in agreement with previous reports detailing the recombination efficiency of the Alb-Cre transgene and consistent with the fact that hepatocytes make up roughly $80 \%$ of liver mass (47). Indeed, expression of $I g f 1$ was reduced by more than $95 \%$, and expression of Igfals was reduced by $88 \%$ in male JAK2L versus control mice $(P<0.001$; Figure 1A). Expression of Iff $1 r, I g f b p 3, G h, G h r, G b r h$, and Ghrbr was not different in JAK2L versus control mice. As expected, mean serum IGF-1 levels were reduced by $95.6 \%$ and $93 \%$ in male and female JAK2L versus control mice $(P<0.001$; Figure 1B), while mean serum GH concentrations were increased $227 \%$ and $1,040 \%$ in male and female JAK2L versus control mice (male JAK2L vs. control, $P<0.001$, and female JAK2L vs. control, $P<0.001$; Figure $1 \mathrm{C}$ ). There were no differences in body weight at birth; however, JAK2L mice had a modest reduction in weight starting at age 45 days. This was more pronounced in male mice $(26.2$ vs. $31.1 \mathrm{~g}, P<0.01$, Figure
1D). The difference in body weight remained between $8 \%$ and $15 \%$ through 65 days. However, when the animals were weighed at 20 weeks of age, the difference in weight was much greater, with male JAK2L mice being 33\% smaller (29.6 vs. $43.9 \mathrm{~g}, P<0.001$, Figure 1D). JAK2L male mice were also $10 \%$ shorter when measured from the base of the tail to the tip of the nose $(9.8 \mathrm{vs} .10 .9 \mathrm{~cm}, P<0.001)$. Taken together, these data strongly suggest that there is a nearcomplete deletion of Jak2 from hepatocytes of JAK2L mice, resulting in near total reduction in expression of Igfl and of Igfals, with similar near-complete abrogation of serum IGF-1 and a concomitant increase in serum GH levels. There was a modest reduction in body weight and a smaller, but significant reduction in length.

JAK2L mice develop profound hepatic steatosis. The livers of JAK2L mice (Figure 2B) were grossly enlarged and yellow even as early as age 4 weeks, and by 8 weeks, the difference between JAK2L and con- 

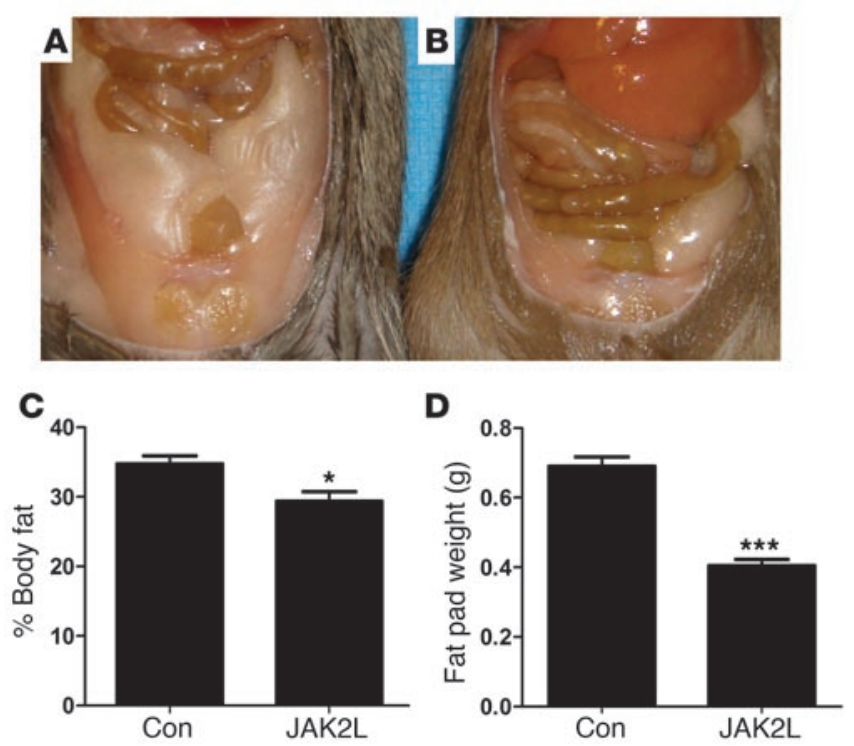

Figure 3

Decreased adiposity in 20-week-old JAK2L mice. (A) Appearance of mesenteric and omental fat in control mice. (B) Decreased adiposity in JAK2L mice. The enlarged, pale, yellow liver is also visible. (C) Percent body fat as determined by DXA scanning in control and JAK2L mice ( $n=5$ for each group). (D) Epididymal fat pad weight of control and JAK2L mice ( $n=5$ for each group). Male mice were used exclusively in the experiments in this figure. Values are expressed as mean \pm SEM. ${ }^{*} P<0.05,{ }^{* \star *} P<0.001$.

trol livers (Figure 2A) was dramatic. Livers were excised en bloc and weighed, and samples were either fixed in $4 \%$ paraformaldehyde (for H\&E) or snap frozen, embedded in OCT (for oil red O staining), and sectioned. As a percentage of total body weight, the livers of JAK2L and control mice were $10.9 \%$ and $5.5 \%$, respectively $(P<0.001$; Figure 2C). Histologic analysis revealed that in JAK2L mice, hepatocytes were diffusely enlarged by clear, sharply bordered cytoplasmic vacuoles (Figure $2 \mathrm{~F}$ ) when compared with control sections (Figure 2D). When sections were stained with oil red $\mathrm{O}$, there was minimal lipid content in the control livers (Figure 2E), while cytoplasmic vacuoles in JAK2L livers stained pink with lipids and neutral TG (Figure 2G). The livers of these younger JAK2L animals had a predominance of macrovesicular steatosis as shown in Figure 2, F and G. While there was no appreciable inflammation in the 8-week-old animals, a cohort of 20-week-old animals had diffuse moderate to severe micro- and macrovesicular hepatocellular steatosis and accompanying mild lobular inflammation and fibroplasia, all of which are seen in non-alcoholic steatohepatitis (NASH; Supplemental Figure 1; supplemental material available online with this article; doi:10.1172/JCI42894DS1).

To determine which lipid fraction(s) were increased in the mutant livers, we next homogenized livers and ran the individual extracts on a TLC plate. As shown in Figure $2 \mathrm{H}$, there was a dramatic increase in the density of the band corresponding to TGs in JAK2L versus control mice. We diluted the JAK2L samples 1:10, and there was still a significant increase in the TG band. There was also a modest increase in the content of sterol esters in the JAK2L livers, but there were no other notable differences. Next, we measured TG and cholesterol content of the liver extracts using a colorimetric assay. Here, TG content was increased 20 -fold in
JAK2L livers versus control (233.8 vs. $11.2 \mathrm{mg} / \mathrm{g}, P<0.0001$, Figure 2I). Cholesterol content was increased 5 -fold (13.52 vs. $2.48 \mathrm{mg} / \mathrm{g}$, $P=0.0005$, Figure 2J).

JAK2L mice have increased plasma FFAs and decreased body fat. We next carefully determined the basic metabolic parameters of JAK2L mice. As detailed in Supplemental Table 1, there were no significant differences in routine analytes, with the exception of a mild increase in aspartate and alanine transaminases (AST and ALT). There were no differences in fasting plasma lipids, and notably, there was no difference in plasma TG levels. However, plasma FFAs were increased in JAK2L versus control mice ( $1.28 \pm 0.11$ vs. $0.79 \pm 0.07 \mathrm{mmol} / \mathrm{l}$, $P<0.01)$. There was also an increase in serum leptin concentration in JAK2L mice ( 19.87 vs. $8.30 \mathrm{ng} / \mathrm{ml}, P<0.01)$, but there were no differences in plasma insulin.

To determine how loss of JAK2 in the liver would affect glucose and insulin homeostasis, we next performed insulin and glucose tolerance tests in JAK2L and control mice and found that there were no significant differences between JAK2L and control mice in either assay (Supplemental Figure 2, A and B).

Careful examination of the 20 -week-old cohort of mice revealed that JAK2L mice were leaner than their littermate controls. Grossly, there was a clearly visible and significant reduction in mesenteric/ omental adiposity in JAK2L (Figure 3A) versus control mice (Figure $3 \mathrm{~B}$ ). Next, we performed dual energy X-ray absorptiometry (DXA) on this older cohort and found that there was a significant reduction in percent body fat in JAK2L versus control mice $29.39 \%$ vs. $34.73 \%, P<0.05$, Figure $3 \mathrm{C}$ ). Since this method captures fat in adipose tissue as well as liver and thus underestimates loss of body fat, we examined mass of epididymal fat pads and found a $40 \%$ reduction in JAK2L versus control male mice ( 0.40 vs. $0.69 \mathrm{~g}$, $P<0.0001$, Figure 3D).

Abrogation of $G H$ secretion rescues the fatty liver phenotype in JAK2L mice. The above data demonstrated that the loss of JAK2 in the liver led to near total reduction of plasma IGF-1 and a concomitant increase in serum GH. JAK2 mice were significantly leaner and had increased levels of plasma FFA. FL was not reported in previously published mouse models of GH deficiency or excess or in mice with abrogation of GH signaling globally $(24,25$, 33-37). However, FL was found in mice with liver-specific deletion of STAT5AB and GHR $(14,30)$. Furthermore, GH has been described to promote lipolysis and increase plasma levels of FFA $(44,48)$. Therefore, we reasoned that the FL phenotype in JAK2L mice might result from dysregulated $\mathrm{GH}$ secretion leading to the observed increase in FFA and decrease in body fat rather than directly from the loss of JAK2 in the liver.

To determine the influence of increased GH secretion on FL in JAK2L mice, we crossed JAK2L mice to little mice $(36,37,49)$. Little mice are unable to respond to GH-releasing hormone (GHRH) due to a point mutation in the GHRH receptor and are therefore unable to secrete GH from the anterior pituitary gland. Animals homozygous for this mutation $\left(l i t^{\mathrm{m} / \mathrm{m}}\right)$ have a dramatic reduction in circulating GH, while heterozygous mice $\left(\mathrm{lit}^{\mathrm{m} / \mathrm{+}}\right)$ are indistinguishable from wild-type (36). Offspring from this cross were viable and born at expected ratios. Since our work with little and JAK2L mice showed no differences between heterozygous-deficient and wild-type mice, we used both single and double heterozygous animals interchangeably and refer to them as control. The cross was designed to generate and compare animals of 4 genotypes, including: control/control (Con-Con), $\mathrm{lit}^{\mathrm{m} / \mathrm{m}} / \mathrm{control}$ (Lit-Con), control/ JAK2L (Con-JAK2L), lit ${ }^{m / m} / \mathrm{JAK} 2 \mathrm{~L}$ (Lit-JAK2L). 

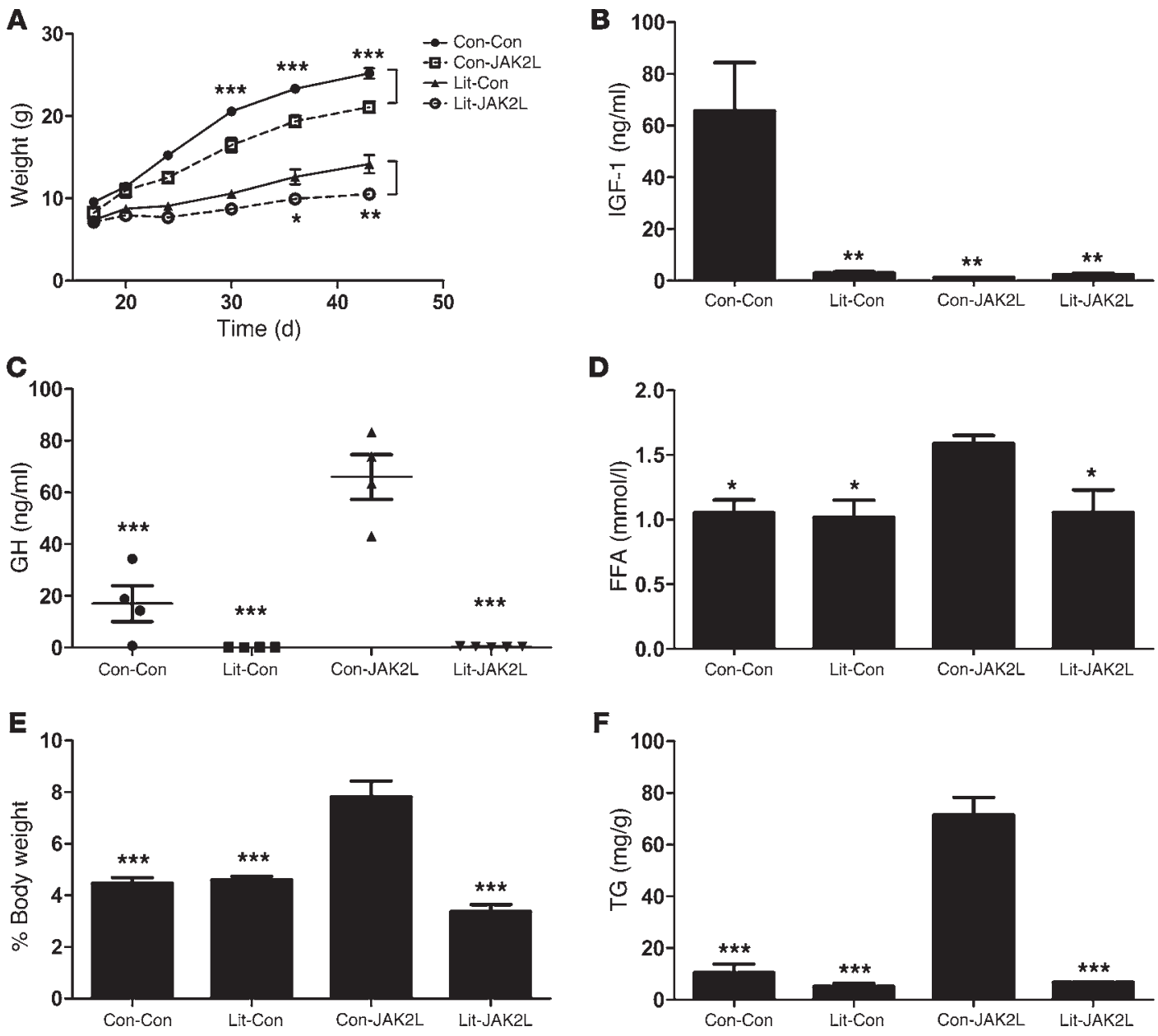

Figure 4

Abrogation of $\mathrm{GH}$ secretion by a genetic cross to $\mathrm{GH}$-deficient little mice rescues the fatty liver phenotype in JAK2L mice. (A) Postnatal weights of male offspring from each of 4 groups from the JAK2L-little intercross ( $n=8-10$ for each time point). (B) Serum concentrations of IGF-1 in the indicated groups ( $n=5$ for each group). All comparisons are to Con-Con. (C) Serum concentrations of GH in indicated groups ( $n=5$ for each group). All comparisons are to Con-JAK2L. (D) Plasma FFA in the indicated groups ( $n=5$ for each group). All comparisons are to Con-JAK2L. (E) Liver weight normalized to body weight is expressed as percent body weight for the indicated groups ( $n=5$ for each group). All comparisons are to Con-JAK2L. (F) Quantity of TG in liver extracts from the indicated groups ( $n=5$ for each group). All comparisons are to Con-JAK2L. Male mice were used exclusively in the experiments in this figure. All values are expressed as mean $\pm \mathrm{SEM} ;{ }^{*} P<0.05,{ }^{* \star} P<0.01,{ }^{\star * \star} P<0.001$.

We weighed male animals from each of the 4 groups at regular intervals starting at 17 days of age, and as expected Lit-Con animals were smaller than littermate Con-Con animals at each time point starting at 20 days (Figure 4A). As seen with JAK2L animals, Con-JAK2L animals were also smaller than Con-Con animals at each time point starting at 30 days. Lit-JAK2L animals were the smallest of the 4 groups and were significantly smaller than each of the other groups at 36 and 43 days. At 43 days, they were $25 \%$ smaller than Lit-Con littermates (10.53 vs. 14.19 g, $P<0.01$, Figure 4A). As expected, Lit-Con mice had low serum IGF-1 and low GH levels, while Con-JAK2L animals had low IGF-1 and elevated serum GH levels; Lit-JAK2L animals had both low IGF-1 and low serum GH levels (Figure 4, B and C). Plasma FFA levels were 1.05, $1.02,1.59$, and $1.06 \mathrm{mmol} / \mathrm{l}$ in Con-Con, Lit-Con, Con-JAK2L, and Lit-JAK2L mice, respectively $(P<0.05$ for all comparisons vs. ConJAK2L, Figure 4D). Strikingly, the FL phenotype was completely rescued in Lit-JAK2L animals. The size of the livers was no differ- ent from that of control (3.38\% vs. $4.47 \%$ body weight, Lit-JAK2L vs. Con-Con, $P=\mathrm{NS}$ ); however, the Lit-JAK2L livers were significantly smaller than Con-JAK2L livers (3.38\% vs. $7.83 \%$ body weight, Lit-JAK2L vs. Con-JAK2L, $P<0.001$, Figure 4E). Lit-JAK2L livers also appeared normal histologically, and the levels of liver TG were also completely normal in the compound mutant Lit-JAK2L animals (6.69 vs. $10.53 \mathrm{mg} / \mathrm{g}$, Lit-JAK2L vs. Con-Con, $P=$ NS, Figure $4 \mathrm{~F})$ and were significantly reduced as compared with Con-JAK2L livers $(6.69$ vs. $71.57 \mathrm{mg} / \mathrm{g}, P<0.001$, Figure $4 \mathrm{~F})$. The results of this cross demonstrated that both the excess FFA and the FL phenotype observed in JAK2L mice were normalized in mice unable to augment GH secretion. This suggested that the FL phenotype did not result entirely as a direct consequence of alterations in JAK2 or $\mathrm{GH}$ signaling in hepatocytes.

Fatty liver in JAK2L mice may result from increased uptake of non-esterified FFAs through induction of the fatty acid transporter CD36. Interpretation of published data suggested that while excessively high levels 
A

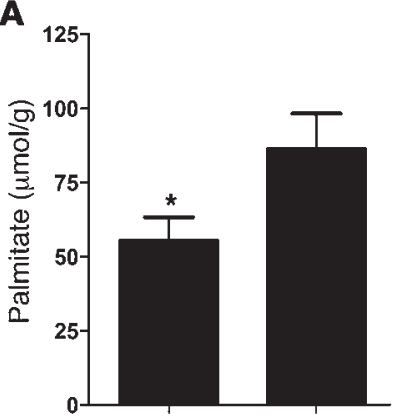

D

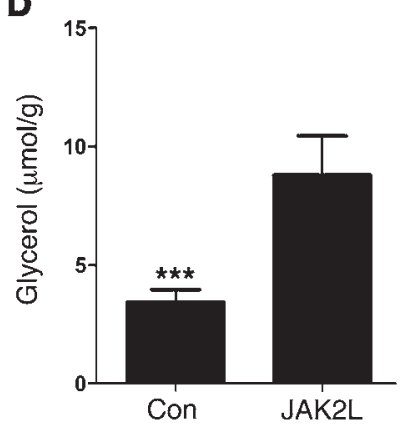

B

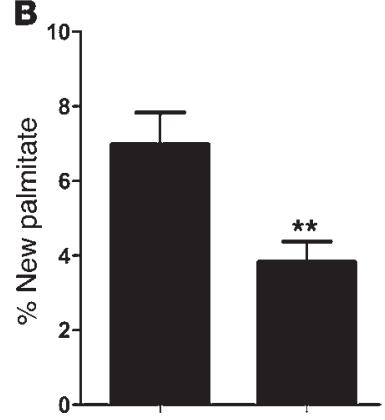

E

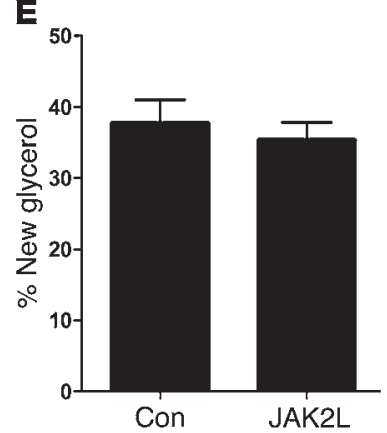

C

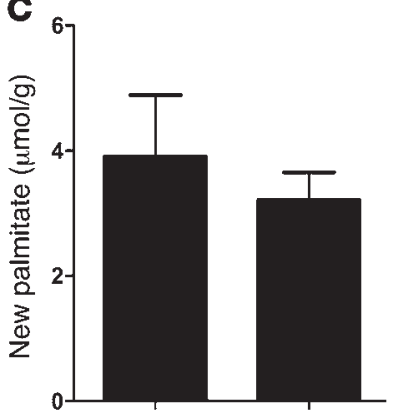

F

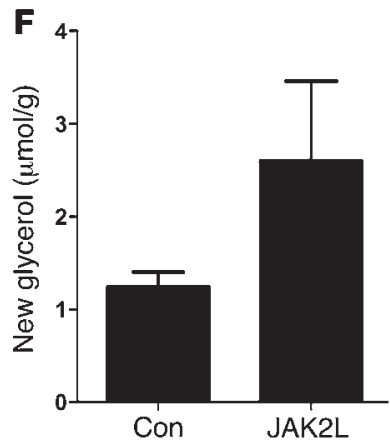

\section{Figure 5}

De novo lipogenesis is unchanged in 4-week-old JAK2L mice. Total palmitate (A) and glycerol (D) content of JAK2L and control livers as determined by direct measurement expressed as $\mu \mathrm{mol} / \mathrm{g}$ tissue. Fractional new synthesis of palmitate (B) and glycerol (E) in JAK2L and control livers was assessed after injection of ${ }^{2} \mathrm{H}_{2} \mathrm{O}$ and determination of ${ }^{2} \mathrm{H}$ labeling by mass spectrometry. Absolute amount of new palmitate (C) and glycerol (F) synthesized during the 4-hour labeling period expressed as $\mu \mathrm{mol} / \mathrm{g}$ tissue. All values are expressed as mean \pm SEM ( $n=6-9$ for both groups) . ${ }^{*} P=0.048,{ }^{\star \star} P=0.0246,{ }^{* * *} P=0.0024$. of serum GH lead to decreases in body adiposity and increases in plasma FFA levels $(33,43,48,50)$, increased GH alone is not sufficient to cause FL (33). It is therefore unlikely that FL in the JAK2L mice resulted from the increase in GH-mediated lipolysis alone, and a model could be postulated whereby FL depends on both the lipolytic effects of excess $\mathrm{GH}$ and a second effect mediated directly by the loss of JAK2 in hepatocytes.

The TG content of hepatocytes is determined by the relative balance of input (de novo synthesis and non-esterified FFA [NEFA] uptake) and output (oxidation and export) mechanisms. To determine the rates of de novo lipogenesis in liver, in vivo, we first directly measured the liver content of TG, cholesterol, palmitate, oleate, stearate, and linoleate. Next, we injected ${ }^{2} \mathrm{H}_{2} \mathrm{O}$ into 4-week-old mice and measured ${ }^{2} \mathrm{H}$ labeling of each by mass spectrometry. Consistent with results of the colorimetric assay (Supplemental Figure 3), and consistent with prior reports detailing the age-dependent activity of the Alb-Cre (47), at 4 weeks of age there was a significant increase in palmitate (Figure 5A) and glycerol (Figure 5D) content in the livers of JAK2L mice. There was no difference in cholesterol, but the total amount of palmitate, linoleate, and oleate was significantly increased, while the amount of stearate was decreased in JAK2L livers (Supplemental Figure 4). The percentage of new palmitate or glycerol synthesized was determined by adjusting for ${ }^{2} \mathrm{H}$-labeled water content. The percentage of new palmitate synthesized was decreased in JAK2L versus control livers (Figure $5 \mathrm{~B}$ ), while there was no difference in the percentage of new glycerol synthesized (Figure 5E). By multiplying the percentage of newly synthesized by the total content, we were able to derive the absolute amount synthesized in the 4-hour labeling period for each component and found that there were no differences between JAK2L and control livers in the content of newly synthesized palmitate (Figure 5C). However, there was a trend toward an increase in glycerol synthesis (Figure 5F). To measure TG secretion, in vivo, we injected WR-1339 and determined that there was no defect in TG secretion in JAK2L mice (Supplemental Figure 5).
Next, we performed microarray analysis of gene expression using the Affymetrix GeneChip Mouse Gene 1.0 ST Array. We compared control and JAK2L livers separately in males and females using 3 individual livers for each group. We determined that there was not a significant increase in expression of genes regulating synthesis or TG export or a decrease in genes regulating oxidation of fatty acids in male or female JAK2L livers. In fact, there was an increase in expression of many genes implicated in fatty acid oxidation (Supplemental Table 2). There was an increase in expression of $S c d 2$ in female JAK2L versus control mice, and in Scd4 in male JAK2L versus control mice (Supplemental Table 2). Uptake of NEFA into hepatocytes is thought to be regulated by at least two classes of transporters, the slc27a fatty acid transport protein family and FAT (or Cd36) (51). Strikingly, expression of Cd36 was increased more than 16 -fold in male JAK2L versus control livers (Figure 6A), while expression of each of the slc27a gene products was unchanged, except for Slc27a2 (FATP2), which was increased 1.2-fold in JAK2L versus control liver (Figure 6B). We also measured the CD36 protein content in both liver and heart by Western blot analysis. As shown in Figure 6C, there was a significant increase in CD36 content in the livers of JAK2L versus control animals. Heart tissue from CD36-knockout and control animals was used as a reference to identify the $\mathrm{CD} 36$ band. There was no appreciable difference in CD36 content in heart tissue (Supplemental Figure $6 \mathrm{~A})$. When we quantified the results, there was a 4 -fold increase in Cd36 content in the livers of JAK2L animals (Figure 6D, $P=0.015$ ), while there was no difference in the content of CD36 in heart (Supplemental Figure 6B, $P=\mathrm{NS}$ ). These data are consistent with previously published data showing that GH signaling negatively regulates expression of Cd36 (52). However, while CD36 is not normally expressed at high levels in the liver, its expression might be increased in the presence of excess plasma FFA (53). Therefore, to specifically determine the effect of the loss of GH signaling in hepatocytes on expression of $C d 36$, we next measured $C d 36$ expres- 
A

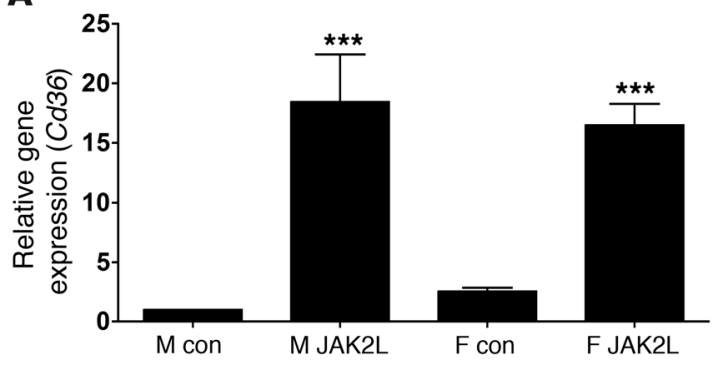

B

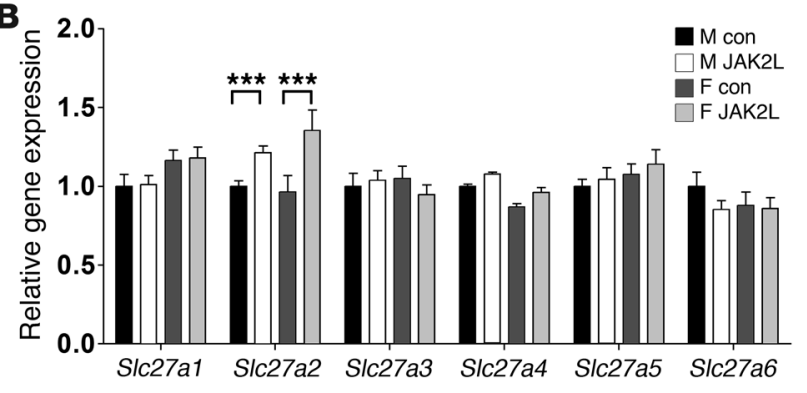

C

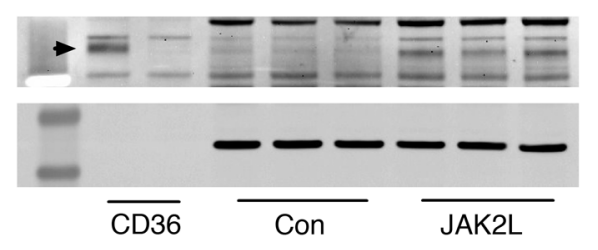

D

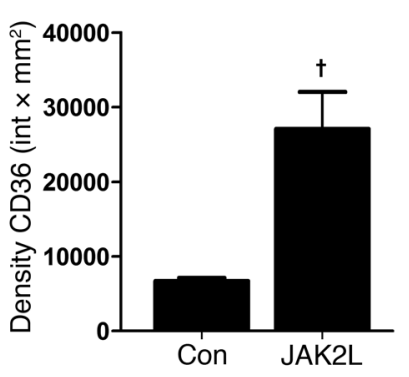

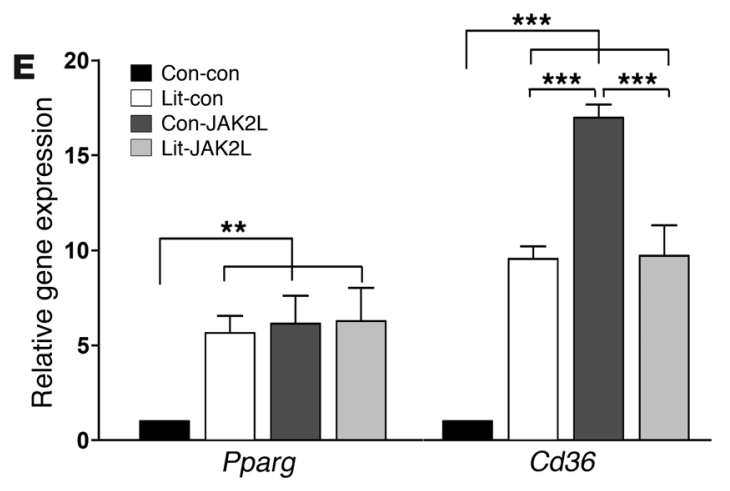

$\mathbf{F}$

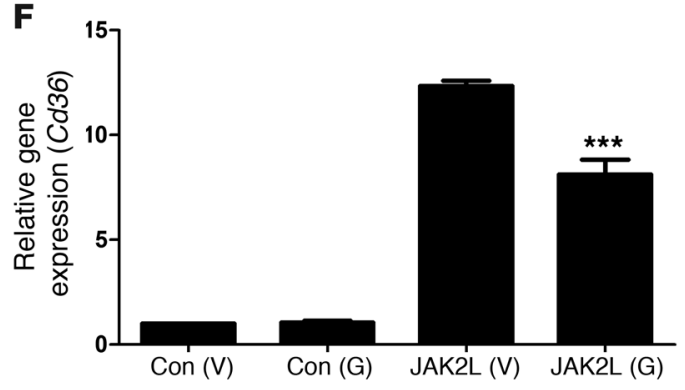

G

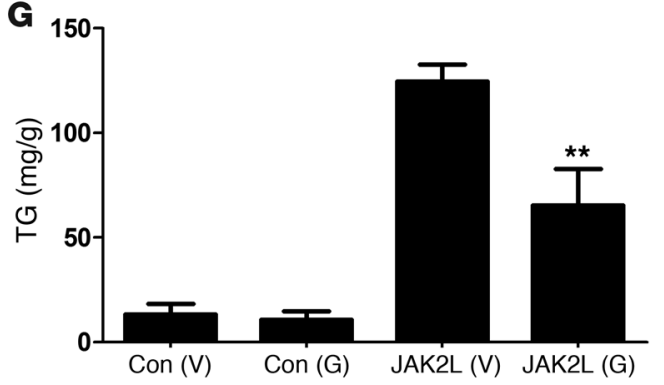

Figure 6

Expression of FAT (Cd36) is significantly increased in livers of JAK2L mice and augments uptake of plasma FFA, leading to FL. Normalized expression of Cd36 (A) and S/c27a genes (B) in livers of male and female JAK2L and control adult mice. Values are derived from Affymetrix Mouse Gene 1.0 ST arrays and are normalized to male control levels ( $n=5$ for each group). (C) CD36 and actin Western blots. Individual liver samples $(n=3)$ were incubated with antibodies against CD36 (upper blot) and actin (lower blot). The first lane is molecular weight standards (upper blot, $62 \mathrm{kDa}$; lower blot, 49 and $38 \mathrm{kDa}$ ). Lanes 2 and 3 (labeled CD36) are heart tissue from wild-type and CD36-knockout mice. Lanes 4-6 and 7-9 are liver samples from control and JAK2L mice, respectively. The arrowhead points to the CD36 band. (D) Quantified density (intensity $\times \mathrm{mm}^{2}\left[\right.$ int $\left.\times \mathrm{mm}^{2}\right]$ ) of the CD36 bands from the liver blot in C. (E) Normalized expression of Pparg and Cd36 from livers from each of 4 groups from the JAK2L-little intercross ( $n=3-4$ for each group). Values are derived from real-time quantitative PCR experiments and are normalized to male control levels. Specific comparisons are indicated. (F) Normalized expression of Cd36 from livers of male control and JAK2L mice after a 2-week treatment with the PPAR $\gamma$-specific antagonist GW9662 (G) (4 mg/g) or vehicle (V) ( $n=5$ for each group). (G) Quantity of TG in liver extracts from the mice in F. All values are expressed as mean \pm SEM. ${ }^{\dagger} P=0.015,{ }^{* *} P<0.01,{ }^{* * *} P<0.001$.

sion in livers from Lit-JAK2L animals using quantitative RT-PCR. Since the Lit-JAK2L animals have normal levels of FFA, these animals provided a means to separate the effects of increased plasma FFA from JAK2 signaling on expression of Cd36 in hepatocytes. As shown in Figure 6E, the expression of Cd36 remained increased in Lit-JAK2L livers as compared with control, suggesting that the increase in Cd36 expression was at least partially due to the loss of JAK2 signaling in hepatocytes and independent of plasma levels of FFA. However, there was also an increase in expression of $C d 36$ in Con-JAK2L versus both Lit-Con and Lit-JAK2L, which suggests that there is likely an additional minor increase in $C d 36$ expression resulting from increased plasma FFA levels.
Since CD36 is known to be under the control of PPAR $\gamma$ (45), we measured expression of Pparg, which was likewise increased in Lit-Con, Con-JAK2L, and Lit-JAK2L versus control mice (Figure $6 \mathrm{E})$. To specifically test the effect of inhibiting CD36 expression on the development of fatty liver in JAK2L mice, we treated a group of 4-week-old JAK2L mice with the PPAR $\gamma$ antagonist GW9662. This compound has been shown previously to decrease the expression of Cd36 in mouse liver and to decrease hepatic steatosis in mice with liver-specific deletion of histone deacetylase 3 (HDAC3) (54). We treated a cohort of younger animals for 2 weeks at a dose $4 \mathrm{mg} / \mathrm{g}$ body weight and found that there was a $31 \%$ reduction in the expression of $C d 36$ (Figure $6 \mathrm{~F}$ ) and a $48 \%$ reduction in liver 


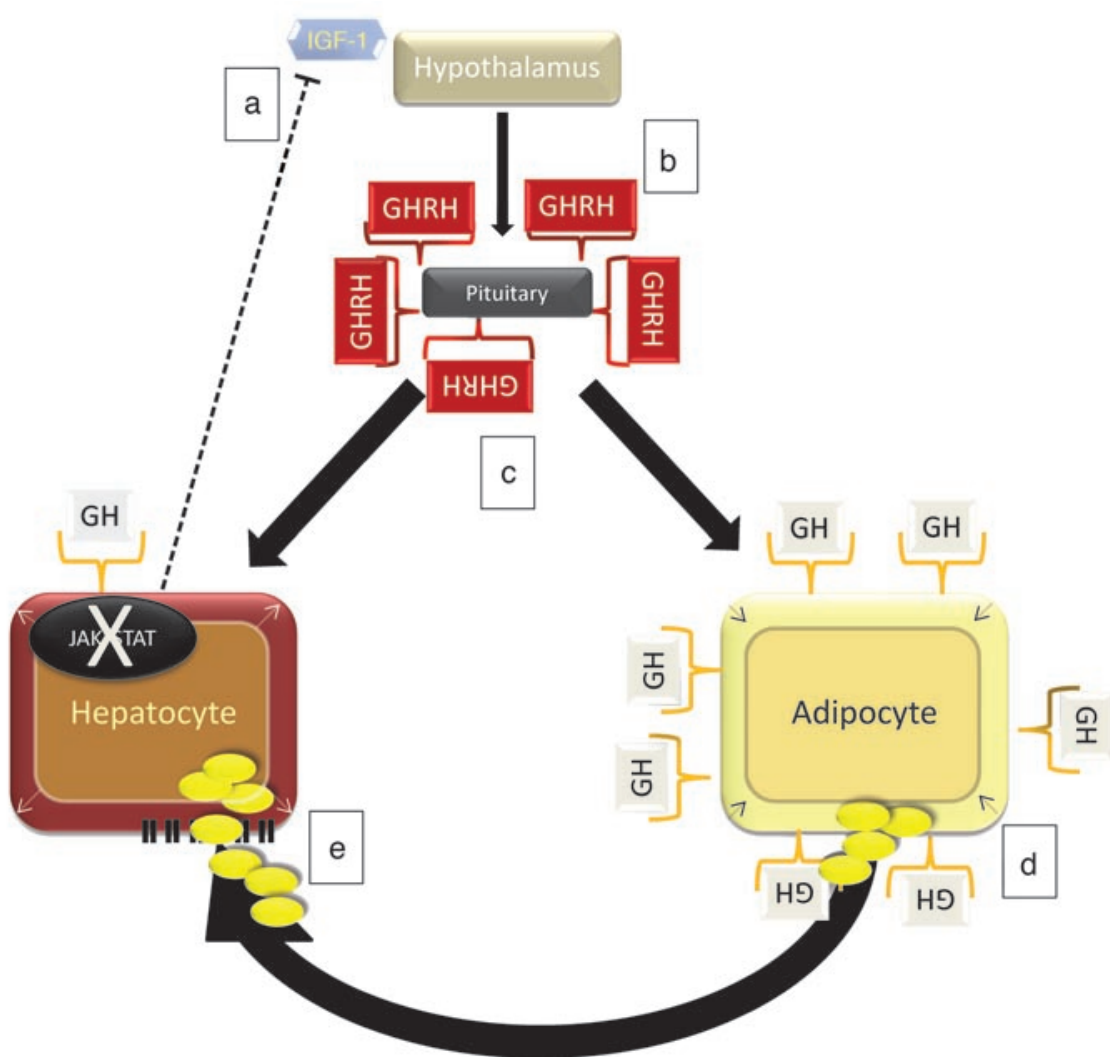

\section{Figure 7}

Proposed model of the mechanism of increased TG content in JAK2L livers. Model depicting the effect of deletion of JAK2 from hepatocytes leading to (a) a decrease in IGF-1 and a release of feedback inhibition in the hypothalamus, (b) an increase in concentration of $\mathrm{GHRH}$, (c) an increase in the secretion of GH from the pituitary, leading to (d) an increase in GH signaling in adipocytes and presumed increase in $\mathrm{GH}$-mediated lipolysis and liberation of FFA into the plasma, and finally (e) an increase in expression of CD36 in hepatocytes (as a result of decreased $\mathrm{GH}$ signaling) and therefore augmented uptake of the increased levels of plasma FFA and development of FL.
TG content in JAK2L animals treated with GW9662 versus those treated with vehicle (Figure 6G).

Overall, these data suggest a model as depicted in Figure 7, where the loss of JAK2 in hepatocytes leads to (a) a reduction in serum IGF-1. This causes (b) a release of inhibition at the level of the hypothalamus, which leads to (c) an increase in circulating GH. GH signaling remains intact in adipocytes, where (d) it leads to liberation of plasma FFA through stimulation of lipolysis. (e) The excess FFAs are then taken up by the GH-resistant hepatocyte through the upregulation of CD36.

\section{Discussion}

NAFLD is an underrecognized and increasingly prevalent condition that remains poorly understood. The recent publications showing FL in association with liver-specific deletion of GHR and STAT5 have focused attention on GH signaling and its role in the development of NAFLD and associated conditions $(14,30$, 55). Indeed, GH has long been implicated in the development of liver steatosis, yet the precise role of GH remains confusing, with reports that administration of GH both causes and cures FL (31, 32). Furthermore, no published mouse models of GH excess or deficiency have described FL (24, 33-37). Finally, while liver-specific disruption of GH signaling has now been shown to cause FL, surprisingly, FL has not been described in any mouse models with global disruption of GHR or STAT5 or in mice with liver-specific deletion of IGF-1 $(24,25,29)$.

We set out to determine the effect of liver-specific deletion of JAK2 in mice and were not at all surprised to observe that these JAK2L mice developed early and severe FL. In fact, the degree of fat accumulation in the livers of JAK $2 \mathrm{~L}$ mice was significantly greater than that observed in the liver-specific deletion of either GHR or STAT5, and the degree of steatosis was among the most severe of all genetic models of NAFLD in the published literature. The 20-week-old cohort of animals showed moderate to severe hepatocellular lipidosis, with mild accompanying foci of lobular inflammation and perisinusoidal fibrosis. These lesions resembled morphologically those seen in NASH, though without all of the features required or consistent with the diagnosis of NASH in humans. This shows that simple hepatic steatosis observed in younger mice progresses to lesions resembling mild NASH.

There were some differences between the JAK2L mice and the prior reports of the liver-specific deletions of GHR (GHRLD) and STAT5. Most notably, GHRLD mice were insulin resistant and glucose intolerant, while the JAK2L mice had normal glucose and insulin homeostasis (30). This difference was unexpected and remains unexplained. One could speculate that these and other differences in phenotype relate to the fact that loss of JAK2 in hepatocytes is more complicated than simply disrupting GH signaling, with known effects on many other signaling pathways such as leptin and IL-6 $(38,56)$. One other notable difference was that expression of Igfbp3 was not significantly lower in JAK2L mice, while it was modestly reduced in the hepatocyte-specific deletion of STAT5 and was dramatically reduced in the GHRLD mice. However, despite the differences, the fundamental issues were the same. Namely, there was a significant reduction in expression of Igf 1 in the liver, a concomitant near-total reduction in serum IGF-1, and a dramatic increase in serum GH. We observed other consequences of GH excess, including a degree of lipodystrophy with a decrease in total body fat and a rise in levels of plasma FFA. The effects on lipolysis were very similar to those described in humans with acro- 
megaly or in transgenic mice with overexpression of GH $(33,50$, 57). Further, increased visceral adiposity was reported in mice with global disruption of STAT5, and a recent publication described increased body fat in mice with global disruption of GHR $(44,58)$. We reasoned that the development of FL in the liver-specific deletion of STAT5, GHR, and JAK2 were all at least somewhat related to dysregulated GH secretion and concomitant effects of increased $\mathrm{GH}$ on lipolysis. To test the effect of excessive GH secretion on development of FL, we crossed the JAK2L mice with the GH-deficient little mice, and indeed, we found that development of FL was completely rescued in mice unable to augment $\mathrm{GH}$ secretion in the absence of serum IGF-1.

This striking observation demonstrated that the development of FL in all 3 models of liver-specific disruption of GH signaling was due, in part, to the loss of IGF-1-mediated feedback inhibition of $\mathrm{GH}$ secretion and the associated effects of dysregulated $\mathrm{GH}$ secretion on lipolysis. While excess GH secretion was necessary for development of FL in the JAK2L mice, it was also clearly not sufficient. Indeed, there are now 5 distinct classes of mouse models with excess plasma GH or GH action: (a) mice with direct overexpression of $G h(33,59)$; (b) mice with global disruption in GH signaling $(23,24)$; (c) mice with disruption in a negative regulator of $\mathrm{GH}$ signaling $(34,35)$; (d) mice with liver-specific disruption of $\mathrm{GH}$ signaling $(26,30)$; and (e) mice with liver-specific deletion of Igf1 (28). Of these, all except mice in class b would be expected to have increased GH signaling in non-liver tissues, with an increase in lipolysis and at least some increase in levels of plasma FFA. However, of these, only the mice in class $d$ have been shown to develop FL. This suggests that in addition to the increase in lipolysis and in levels of plasma FFA, a second hit is necessary to cause FL. Furthermore, this supports a model in which FL only develops when there is both an increase in the levels of FFA and a disruption in GH signaling in the liver. That is, while mice in class b have a decrease in $\mathrm{GH}$ signaling in the liver, they do not have an increase in lipolysis and therefore have normal or reduced levels of FFA. And indeed, as described above, these mice have increased adiposity, but no FL. On the contrary, mice in classes a, c, and e have increased levels of serum $\mathrm{GH}$ and intact $\mathrm{GH}$ signaling, with concomitant effects on lipolysis. They therefore have increased levels of plasma FFA, but have normal or increased GH signaling in the liver.

The evidence we have accumulated suggests that inhibition of GH signaling in the liver permits increased uptake of plasma FFA. This is apparent only when the levels of plasma FFA are increased. The data on de novo lipogenesis and TG secretion support this model, as while there is a general increase in the content of the FAs and glycerol in JAK2L livers, there is no increase in FA synthesis. In fact, there is a small decrease in the rate of palmitate synthesis. Furthermore, the ratio of oleate to stearate is extremely high, a fact that suggests an increase in stearoyl-CoA desaturase (SCD) activity (60). Consistent with this, we observed significant increases in mouse SCD gene expression. Increases in SCD activity have indeed been reported in human and animals with FL (61). Thus, while there is an increase in liver FA content, there is no increase in the rate of de novo synthesis, and this points strongly toward an increase in the uptake of plasma FA.

Fatty acid transport is thought to occur mainly through the family of slc27a fatty acid transport proteins as well as the scavenger receptor CD36 $(62,63)$. The 16 -fold increase in expression of Cd36 in male JAK2L versus control liver was the sixth highest increase in the entire 25,000-gene Affymetrix array. Expression of CD36 is reported to be very low in normal mouse liver, and in our control samples, the expression at both the RNA and protein levels was indeed low. Prior reports have shown that increased expression of Cd36 can augment uptake of FA (64). Therefore, we propose a model whereby the increased levels of CD36 in JAK2L livers augments uptake of plasma FFA as depicted in Figure 7. While the increase in Cd36 expression was partially attenuated in Lit-JAK2L mice, there was still a 10-fold increase in these animals (versus control), with normal levels of plasma FFA, suggesting that GH signaling itself represses expression of $C d 36$. In addition, the level of $C d 36$ expression was very similar to that in Lit-Con mice.

Interestingly, the expression of Pparg was increased dramatically in JAK2L liver and was increased to a similar degree in Lit-Con, Con-JAK2L, and Lit-JAK2L liver. CD36 is a well-known transcriptional target of PPAR $\gamma(65,66)$. Previous work has implicated GH signaling (through STAT5b) in the transcriptional repression of PPAR $\gamma$ (46). While GH was shown to repress the transcriptional activity of PPAR $\gamma$, the effect did not appear to be mediated directly through a physical interaction between STAT5b and PPAR $\gamma$ (46). Exactly how PPAR $\gamma$ is repressed by GH remains unclear, but one particularly intriguing idea is that this effect is mediated through HDAC3. Indeed, hepatocyte-specific deletion of HDAC3 resulted in de-repression of PPAR $\gamma$ and CD36 expression and in the accumulation of TG in the liver (54). Treatment with a PPAR $\gamma$ inhibitor reduced expression of CD36 as well as the severity of steatosis in mice with hepatocyte-specific deletion of HDAC3 (54). In JAK2L mice, treatment with GW9662 for 2 weeks reduced the expression of Cd36 in liver. These results support the hypothesis that transcriptional control of $C d 36$ is downstream of PPAR $\gamma$. In addition, we have shown that by decreasing $C d 36$ expression in liver, the liver TG content is decreased. Overall, these data support our model in which the loss of GH signaling in JAK2L mice likely leads to a release of inhibition of $\mathrm{Cd} 36$ expression.

All of this suggests that abnormal GH signaling would predispose to development of FL in conditions where there are increased levels of plasma FFA, such as starvation (67). Accordingly, administration of a small molecule JAK2 inhibitor would not be expected to cause FL unless there was concomitant increase in plasma FFA or if there was preferential drug uptake or action in the liver as one might expect with small molecule compounds. However, formal evaluation of the liver toxicity of these compounds remains to be determined. Furthermore, chronic inhibition of JAK2 might also be expected to result in increased visceral adiposity. The effect of JAK2 on GH-mediated lipolysis in adipocytes is of great interest for future study. Overall, these studies demonstrate what we believe to be a novel mechanism of FL and provide important insights into the possible effects of JAK2 inhibition in humans. At the core, the liver-specific deletion of JAK2 causes a remarkable redistribution of fat from peripheral stores to the liver. This may have implications for understanding the pathogenesis of NAFLD as well as the potential safety of JAK2 inhibition, but also suggests multiple lines of future research aimed at completely understanding the effect of GH signaling on fat metabolism and on lipid flux in hepatocytes.

\section{Methods}

Mice. Mouse care and use for these studies were approved by the UCSF Institutional Animal Care and Use Committee. Mice were maintained on a 12-hour light/12-hour dark cycle and were fed PicoLab Mouse Diet 20 (*5058) ad libitum except as noted otherwise. Mice with loxP sites flanking the first exon of Jak2 were generated and described previously (42). Hepato- 
cyte-specific JAK2-deficient mice (JAK2L) were generated by mating floxed JAK2 mice (in a mixed [C57BL/ $6 \times 129 / \mathrm{Sv}$ ] background) to mice carrying an Alb promoter-regulated Cre transgene on a $100 \%$ C57BL/6 background purchased from The Jackson Laboratory (68). Male and female wild-type C57BL/6 mice and little mice carrying the Ghrbrit mutation (referred to as $l t^{m}$ ) were also purchased from The Jackson Laboratory. The little mice are on a $100 \%$ C57BL/ 6 background and were maintained as female lit ${ }^{m / m}$ mated to male lit ${ }^{m /+}$ intercrosses. JAK2L and little mice were intercrossed by mating female $\mathrm{lit}^{m / m}$ with male JAK2L mice and subsequently intercrossing mice heterozygous for the little mutation $\left(\mathrm{lit}^{\mathrm{m} /+}\right)$ with mice carrying both a single copy of the Alb-Cre and a single floxed JAK2 allele. Since of our work with little and JAK2L mice showed no differences between heterozygousdeficient and wild-type mice, we used both single and double heterozygous animals interchangeably and refer to them as "control." The cross was designed to generate and compare animals of 4 genotypes including: control/control (Con-Con), lit $\mathrm{t}^{\mathrm{m} / \mathrm{m}} / \mathrm{control}$ (Lit-Con), control/JAK2L (ConJAK2L), $l i t^{m / m} / \mathrm{JAK} 2 \mathrm{~L}$ (Lit-JAK2L). For all experiments, mice were compared to sex-matched littermate controls. All mice were assayed at the indicated age. All experiments were conducted by investigators blind to genotype and repeated at least twice except where indicated otherwise. The background strain of each line is indicated.

Gene expression. Real-time quantitative PCR was performed using TaqMan primer/probe sets (5'FAM/3'BHQ; Biosearch Technologies) designed using Primer Express software (Applied Biosystems; see Supplemental Table 3 for a complete list and primer/probe sequences). Total RNA was isolated from mouse livers with TRIzol (Invitrogen) extraction, followed by purification with an RNeasy Mini Column (QIAGEN). First-strand cDNA synthesis was performed using the Superscript First-Strand Synthesis System (Invitrogen) and oligo-dT primers. Quantitative real-time PCR reactions were performed in a 384-well format using a Platinum qPCR mix (Invitrogen) and total reaction volumes of $10 \mu \mathrm{l}$ on an ABI 7900HT (Applied Biosystems). Absolute gene expression (gene copy number) was quantified with the method of Dolganov and colleagues using the control genes Gapdh, $\beta$-actin, and cyclophilin (69).

Microarray analysis. Total RNA from 8-week old male and female JAK2L and littermate control livers ( $n=3$ each) was prepared as above. RNA was analyzed using the Agilent 2100 BioAnalyzer. All samples were prepared using Affymetrix WT cDNA Synthesis and Amplification Kits for cDNA synthesis, cRNA amplification, and conversion to sense strand DNA products according to the manufacturer's instructions. Samples were then fragmented and end labeled using Affymetrix WT Target Labeling and Control Reagents Kits according to the manufacturer's instructions. Each sample was then hybridized to an Affymetrix Mouse Gene 1.0 ST array by standard procedures. The data discussed in this publication have been deposited in NCBI's Gene Expression Omnibus and are accessible through GEO Series accession number GSE26188 (http://www.ncbi.nlm.nih.gov/geo/query/ acc.coi $?$ acc $=$ GSE26188).

Histology. Livers were excised en bloc and either fixed in $4 \%$ paraformaldehyde (H\&E) or snap frozen (oil red O). Fixed specimens were processed to paraffin blocks, sectioned, and stained with $\mathrm{H} \& \mathrm{E}$ as well as trichrome. Frozen specimens were embedded in OCT and then sectioned and stained with oil red $\mathrm{O}$ to visualize neutral TGs.

Serum and plasma biochemical and metabolic analyses. Serum chemistry analyses (total protein, albumin, glucose, total bilirubin, alkaline phosphatase, AST, ALT, blood urea nitrogen [BUN], creatinine, and gamma glutamyl transpeptidase [GGT]) were performed at the UCD Comparative Pathology Laboratory using assays from Roche Diagnostics and performed on the Roche Cobas Integra 400 Plus analyzer. Cholesterol and TG content of plasma and lipoproteins were determined by automated chemical analysis (70). HDL cholesterol (HDL-C) was measured after precipitation of
apoB-containing lipoproteins with dextran sulfate and magnesium (71). LDL cholesterol (LDL-C) was calculated by using the Friedewald equation (72). Standards were provided by the Centers for Disease Control. Plasma leptin (Mouse Leptin ELISA Kit, Crystal Chem Inc.) and insulin (Ultra Sensitive Mouse Insulin ELISA Kit, Crystal Chem Inc.) concentrations were determined using commercially available ELISAs according to the manufacturer's protocol. FFA concentration was determined using $5 \mu \mathrm{l}$ of plasma drawn into tubes containing EDTA according to the manufacturer's protocol (Wako). Serum GH (Millipore) and IGF-1 (R\&D Systems) levels were determined using commercially available ELISA kits according to the manufacturer's protocol.

Tissue lipid content. Mouse liver was homogenized in buffer A $(250 \mathrm{mM}$ sucrose, $50 \mathrm{mM}$ Tris, $\mathrm{pH}$ 7.4), and a sample of lysate was used to determine TG content (Infinity TG Reagent) and cholesterol content (Wako Diagnostics Total Cholesterol Reagent) according to the manufacturers' instructions. Neutral lipid was also visualized by TLC (using solvent hexane/diethyl ether/glacial acetic acid, 80:20:1) following extraction with chloroform/methanol (2:1).

Body composition analysis. Lean and fat mass were determined by DXA. Live animals were anesthetized with isoflurane and scanned on a Lunar PIXImus densitometer (GE Medical Systems). Percent lean and fat were determined by manually dividing mass by actual weight.

Insulin and glucose tolerance tests. Blood glucose determinations were made using the Bayer Contour Glucometer and strips. For both assays, 10 male JAK2L and littermate control animals (8 weeks of age) were used. Animals were fasted for 4 (insulin) or 12 (glucose) hours before injection. Baseline glucose was measured, and then either human insulin $(1 \mathrm{U} / \mu \mathrm{l}$ at $1 \mathrm{U} / \mathrm{kg})$ or glucose $(200 \mathrm{mg} / \mathrm{ml})$ was injected i.p. Blood glucose was then measured from the tail vein at 30,60 , and 120 minutes after injection. Results were normalized to baseline glucose values.

TG secretion. Ten male JAK2L and littermate control animals (8 weeks of age) were fed a fat-free diet (960238, MP-Biomedicals) containing vitaminfree casein (20\%), DL-methionine (0.3\%), and sucrose (60.2\%) for 4 hours before the beginning of the protocol and throughout the experiment. The animals were anesthetized with isoflurane, and blood was drawn via retroorbital puncture into tubes containing EDTA. Immediately following the baseline blood draw, animals were injected intravenously with $500 \mathrm{mg} / \mathrm{kg}$ Triton WR-1339 (Sigma-Aldrich) as a $15-\mathrm{g} / \mathrm{dl}$ solution in $0.9 \% \mathrm{NaCl}$. Blood was then drawn as above at 30, 90, and 180 minutes after injection. Plasma TG content was then determined as described above and was normalized to baseline levels.

De novo lipogenesis. TG content and newly synthesized TG/FA levels were measured at the Case Mouse Metabolic Phenotyping Center (CASE MMPC). To enrich body water with approximately $2 \%{ }^{2} \mathrm{H}$, an i.p. injection of labeled water $(20 \mu \mathrm{l} / \mathrm{g}$ body weight of $9 \mathrm{~g} / \mathrm{l} \mathrm{NaCl}$ in $99 \%$ atom percent excess ${ }^{2} \mathrm{H}_{2} \mathrm{O}$ ) was administered to 4-week-old mice. Mice were returned to their cages for 4 hours and allowed ad libitum access to food and ${ }^{2} \mathrm{H}_{2} \mathrm{O}$. The mice were killed, and blood and liver tissue samples were collected and flash frozen in liquid nitrogen. The samples were stored at $-80^{\circ} \mathrm{C}$ until analysis. TG concentrations and de novo lipogenesis were determined as previously described (73). Briefly, total TG, fatty acids, and cholesterol from tissues were isolated using chemical hydrolysis and extraction techniques. The ${ }^{2} \mathrm{H}$-labeled glycerol and palmitate were analyzed after derivatization by mass spectrometry. The ${ }^{2} \mathrm{H}$-labeled TG covalently linked to glycerol measures the amount of newly synthesized TG, while the ${ }^{2} \mathrm{H}$-labeled TG covalently attached to palmitate indicates the amount of new palmitate. In mice given ${ }^{2} \mathrm{H}_{2} \mathrm{O}$ for 4 hours, the contribution of de novo lipogenesis to the pool of TG and palmitate was calculated using the following formula: $\%$ newly made palmitate $=\left(\right.$ total ${ }^{2} \mathrm{H}$-labeled palmitate $\cdot\left[{ }^{2} \mathrm{H}\right.$-labeled body water $\left.\times n]^{-1}\right) \times 100$, where $n$ is the number of exchangeable hydrogens, 
which is assumed to $22(74,75)$. The percentage of total newly made TGglycerol was calculated using the following formula: \% total newly made TG-glycerol $=\left({ }^{2} \mathrm{H}\right.$-labeled TG-glycerol $\left.\cdot\left[{ }^{2} \mathrm{H} \text {-labeled water } \times n\right]^{-1}\right) \times 100$, where ${ }^{2} \mathrm{H}$-labeled TG-glycerol is the M1 isotopomer, ${ }^{2} \mathrm{H}$-labeled water is the average amount labeled in a given mouse, and $n$ is the exchange factor (experimentally determined from the $\mathrm{M} 2 / \mathrm{M} 1$ ratio of TG glycerol). We calculated the total TG pool size ( $\mu \mathrm{mol} / \mathrm{g}$ tissue) in the tissues using the following formula: total pool size of TG $=\left({ }^{2} \mathrm{H}\right.$-labeled TG-glycerol $\cdot\left[{ }^{2} \mathrm{H}-\right.$ labeled water $\left.\times n]^{-1}\right) \times 100$.

GW9662 treatment. The PPAR $\gamma$-specific antagonist was purchased (Cayman Chemical) and prepared as described by Knutson et al. (54). Specifically, a stock solution of GW9662 was made by resuspension in DMSO at a concentration of $20 \mathrm{mg} / \mathrm{ml}$, and this was aliquoted into separate tubes and frozen at $-20^{\circ} \mathrm{C}$. Four cohorts ( $n=4$ each) of animals were used for the study, including (a) JAK2L plus GW9662, (b) JAK2L plus vehicle, (c) control (GW9662), and (d) control (vehicle). The mice were 3-4 weeks of age and were weighed at the beginning of the experiment and then every 3 days until the conclusion. The mice were injected daily for 14 days. The injections were i.p. Each day, an aliquot of stock drug was thawed and then resuspended in DMSO/saline at a final concentration of $4 \mathrm{mg} / \mathrm{g}$ body weight in a final volume of $100 \mu \mathrm{l}$. Vehicle injections contained the same relative content of DMSO and saline. At the conclusion of the experiment, the mice were sacrificed and the organs and blood were harvested for analysis and frozen at $-80^{\circ} \mathrm{C}$. The entire experiment was repeated and the results were pooled.

Western blots. Liver and control (heart) samples (Figure 6C) were homogenized in complete lysis buffer containing $4 \mathrm{ml}$ of $0.5 \mathrm{M}$ Tris, $3 \mathrm{ml}$ of $5 \mathrm{M}$ $\mathrm{NaCl}, 800 \mu \mathrm{l}$ of $250 \mathrm{mM}$ EDTA, and $92.2 \mathrm{ml}$ Milli-Q $\mathrm{H}_{2} \mathrm{O}$. This solution was filter sterilized, and $100 \mu \mathrm{l}$ of Halt Protease and Phosphatase Inhibitor Cocktail (Thermo Scientific) was added per $10 \mathrm{ml}$, just prior to use. A bicinchoninic acid (BCA) protein assay (Pierce) was run for all samples to determine the final loading volume of $125 \mu \mathrm{g}$ of liver protein and $25 \mu \mathrm{g}$ of control (heart) protein. Proteins were separated by SDS-PAGE (Invitrogen) and transferred to nitrocellulose membranes. The membranes were simultaneously incubated with 1:1,000 rabbit anti-mouse CD36 antibody (Novus Biologicals) and 1:1,000 mouse anti-mouse $\beta$-actin antibody (Sigma-Aldrich) overnight at $4{ }^{\circ} \mathrm{C}$, followed by 1:1,000 Alexa Fluor 555 goat anti-rabbit IgG (Invitrogen) and 1:1,000 Alexa Fluor 647 goat anti-mouse IgG (Invitrogen) for 1 hour at room temperature. Proteins were imaged and quantified with the Versadoc Imaging System (Bio-Rad) and quantified intensity was reported (intensity* $\mathrm{mm}^{2}$ ).

Heart samples (Supplemental Figure 6) were homogenized in lysis buffer as previously described, but instead supplemented with one tablet of protease inhibitor cocktail (Complete Mini EDTA-free; Roche Applied Science), $100 \mu \mathrm{l}$ phosphatase cocktail, and $100 \mu \mathrm{l}$ Triton-X per $10 \mathrm{ml}$. Heart protein was loaded at $40 \mu \mathrm{g}$ per well, separated by SDS-PAGE, and transferred to membrane. This membrane was probed with 1:1,000 rabbit anti-mouse CD36 antibody (Novus Biologicals) and 1:5,000 anti-rabbit secondary using the Millipore SNAP ID system, according to the manufacturer's instructions. The membrane was then incubated in SuperSignal West Pico Substrate (Pierce) for 5 minutes and developed on film with 1-minute exposure. The membrane was then stripped using Restore PLUS Western Blot Stripping Buffer (Thermo Scientific), and incubated with 1:5,000 actin antibody overnight at $4^{\circ} \mathrm{C}$, followed by 1:5,000 anti-rabbit secondary antibody for 1 hour at room temperature. Band density was quantified using ImageJ.

Statistics. Student's $t$ test (2-tailed) was used to determine significance in cases where 2 groups were compared. For comparison of 3 or more groups, 1-way ANOVA followed by the Bonferroni post-test was employed. Analysis of 3 or more groups over time or across another variable was carried out using 2-way ANOVA followed by the Bonferroni post-test. An $\alpha$ value of 0.05 was set for all statistical tests. Data are presented as mean \pm SEM, unless otherwise indicated. All statistical analyses were performed in GraphPad Prism version 5 (GraphPad Software).

\section{Acknowledgments}

We thank Robert Farese, Ross Levine, Shaun Coughlin, Robin Shaw, Nico Ghilardi, Clive Pullinger, John Kane, and O.K. Gilman for important discussions of the work; and Irina Movsesyan, Tina Fong, Maya Sukkari, and Chiara Kuryan for outstanding technical assistance. We thank Marian Derby and Eugene Dunn of the UCD Comparative Pathology Laboratory. We thank Michelle Puchowicz and Henri Brunengraber of the CASE MMPC (U24 DK76169) for work on the de novo lipogenesis and important discussions. This work was supported in part by Pilot/Feasibility grant P30 DK026743 from the UCSF Liver Center (to E.J. Weiss) and by NIH grant CA117930 (to K.U. Wagner).

Received for publication March 6, 2010, and accepted in revised form January 5, 2011.

Address correspondence to: Ethan J. Weiss, University of California, San Francisco, Cardiovascular Research Institute, MC:3120, 555 Mission Bay Boulevard South, Room 352Y, San Francisco, California 94158-9001, USA. Phone: 415.514.0819; Fax: 415.502.7949; E-mail: ethan.weiss@ucsf.edu.
1. Angulo P. Nonalcoholic fatty liver disease. $N$ Engl J Med. 2002;346(16):1221-1231.

2. Choi CS, et al. Suppression of diacylglycerol acyltransferase-2 (DGAT2), but not DGAT1, with antisense oligonucleotides reverses diet-induced hepatic steatosis and insulin resistance. J Biol Chem. 2007;282(31):22678-22688.

3. Choi CS, et al. Continuous fat oxidation in acetyl-CoA carboxylase 2 knockout mice increases total energy expenditure, reduces fat mass, and improves insulin sensitivity. Proc Natl Acad Sci US A. 2007;104(42):16480-16485.

4. Michael MD, et al. Loss of insulin signaling in hepatocytes leads to severe insulin resistance and progressive hepatic dysfunction. Molecular Cell. 2000; 6(1):87-97.

5. Lin HZ, Yang SQ, Chuckaree C, Kuhajda F, Ronnet G, Diehl AM. Metformin reverses fatty liver disease in obese, leptin-deficient mice. Nat Med. 2000; 6(9):998-1003.

6. Dentin R, et al. Liver-specific inhibition of ChREBP improves hepatic steatosis and insulin resistance in ob/ob Mice. Diabetes. 2006;55(8):2159-2170.

7. Lee Y, et al. Liporegulation in diet-induced obesity. The antisteatotic role of hyperleptinemia. J Biol Chem. 2001;276(8):5629-5635.

8. Cai D, et al. Local and systemic insulin resistance resulting from hepatic activation of IKK-beta and NF-kappaB. Nat Med. 2005;11(2):183-190.

9. Tilg H, Diehl AM. Cytokines in alcoholic and nonalcoholic steatohepatitis. $N$ Engl J Med. 2000; 343(20):1467-1476.

10. Feingold KR, Grunfeld C. Tumor necrosis factoralpha stimulates hepatic lipogenesis in the rat in vivo. J Clin Invest. 1987;80(1):184-190.

11. Endo M, Masaki T, Seike M, Yoshimatsu H. TNFalpha induces hepatic steatosis in mice by enhancing gene expression of sterol regulatory element binding protein-1c (SREBP-1c). Exp Biol Med (Maywood). 2007;232(5):614-621.

12. Cressman DE, et al. Liver failure and defective hepatocyte regeneration in interleukin-6-deficient mice. Science. 1996;274(5291):1379-1383.

13. McClain CJ, Barve S, Deaciuc I, Kugelmas M, Hill D.
Cytokines in alcoholic liver disease. Semin Liver Dis. 1999;19(2):205-219.

14. Cui Y, et al. Loss of signal transducer and activator of transcription 5 leads to hepatosteatosis and impaired liver regeneration. Hepatology. 2007;46(2):504-513.

15. Ueki K, Kadowaki T, Kahn CR. Role of suppressors of cytokine signaling SOCS- 1 and SOCS-3 in hepatic steatosis and the metabolic syndrome. Hepatol Res. 2005;33(2):185-192.

16. Ueki K, Kondo T, Tseng Y-H, Kahn CR. Central role of suppressors of cytokine signaling proteins in hepatic steatosis, insulin resistance, and the metabolic syndrome in the mouse. Proc Natl Acad SciUS A. 2004;101(28):10422-10427.

17. Jansson JO, Eden S, Isaksson O. Sexual dimorphism in the control of growth hormone secretion. Endocr Rev. 1985;6(2):128-150.

18. Isaksson OG, Eden S, Jansson JO. Mode of action of pituitary growth hormone on target cells. Annu Rev Physiol. 1985;47:483-499.

19. Souza SC, Frick GP, Wang X, Kopchick JJ, Lobo $\mathrm{RB}$, Goodman HM. A single arginine residue deter- 
mines species specificity of the human growth hormone receptor. Proc Natl Acad Sci U S A. 1995 ; 92(4):959-963.

20. Lanning N, Carter-Su C. Recent advances in growth hormone signaling. Rev Endocr Metab Disord. 2006; 7(4):225-235.

21. Levy DE, Darnell JE. STATs: transcriptional control and biological impact. Nat Rev Mol Cell Biol. 2002; 3(9):651-662.

22. Rowland JE, et al. In vivo analysis of growth hormone receptor signaling domains and their associated transcripts. Mol Cell Biol. 2005;25(1):66-77.

23. Davey HW, Xie T, McLachlan MJ, Wilkins RJ, Waxman DJ, Grattan DR. STAT5b is required for GHinduced liver IGF-I gene expression. Endocrinology. 2001;142(9):3836-3841.

24. Zhou Y, et al. A mammalian model for Laron syndrome produced by targeted disruption of the mouse growth hormone receptor/binding protein gene (the Laron mouse). Proc Natl Acad SciUS A. 1997; 94(24):13215-13220.

25. Teglund S, et al. Stat5a and Stat $5 \mathrm{~b}$ proteins have essential and nonessential, or redundant, roles in cytokine responses. Cell. 1998;93(5):841-850.

26. Holloway MG, Cui Y, Laz EV, Hosui A, Hennighausen L, Waxman DJ. Loss of sexually dimorphic liver gene expression upon hepatocyte-specific deletion of Stat5a-Stat5b locus. Endocrinology. 2007; 148(5):1977-1986

27. Wallenius $\mathrm{K}$, et al. Liver-derived IGF-I regulates GH secretion at the pituitary level in mice. Endocrinology. 2001;142(11):4762-4770.

28. Sjogren K, et al. Liver-derived insulin-like growth factor I (IGF-I) is the principal source of IGF-I in blood but is not required for postnatal body growth in mice. Proc Natl Acad Sci U S A. 1999;96(12):7088-7092.

29. Yakar $S$, et al. Inhibition of growth hormone action improves insulin sensitivity in liver IGF-1-deficient mice. J Clin Invest. 2004;113(1):96-105.

30. Fan Y, et al. Liver-specific deletion of the growth hormone receptor reveals essential role of growth hormone signaling in hepatic lipid metabolism. J Biol Chem. 2009;284(30):19937-19944.

31. Braun T, Fábry P, Petrásek R. Influence of previous feeding with a high-fat diet on liver steatosis produced by acute starvation or growth hormone in mice. Experientia. 1963;19:47-48.

32. Takahashi Y, et al. Growth hormone reverses nonalcoholic steatohepatitis in a patient with adult growth hormone deficiency. Gastroenterology. 2007; 132(3):938-943.

33. Orian JM, Seong Lee C, Weiss LM, Brandon MR. The expression of a metallothionein-ovine growth hormone fusion gene in transgenic mice does not impair fertility but results in pathological lesions in the liver. Endocrinology. 1989;124(1):455-463.

34. Greenhalgh CJ, et al. SOCS2 negatively regulates growth hormone action in vitro and in vivo. J Clin Invest. 2005;115(2):397-406

35. Metcalf D. Gigantism in mice lacking suppressor of cytokine signalling-2. Nature. 2000; 405(6790):1069-1073.

36. Lin SC, Lin CR, Gukovsky I, Lusis AJ, Sawchenko PE, Rosenfeld MG. Molecular basis of the little mouse phenotype and implications for cell typespecific growth. Nature. 1993;364(6434):208-213.

37. Eicher EM, Beamer WG. Inherited ateliotic dwarfism in mice. Characteristics of the mutation, little, on chromosome 6. J Hered. 1976;67(2):87-91.

38. Yamaoka K, Saharinen P, Pesu M, Holt V, Silvennoinen $\mathrm{O}$, O'Shea J. The Janus kinases (Jaks). Genome Biology. 2004;5(12):253.

39. Rawlings JS, Rosler KM, Harrison DA. The
JAK/STAT signaling pathway. J Cell Sci. 2004; 117(pt 8):1281-1283.

40. Neubauer H, Cumano A, Müller M, Wu H, Huffstadt $\mathrm{U}$, Pfeffer K. Jak2 deficiency defines an essentialdevelopmental checkpoint in definitive hematopoiesis. Cell. 1998;93(3):397-409.

41. Parganas E, et al. Jak2 is essential for signaling through a variety of cytokine receptors. Cell. 1998; 93(3):385-395.

42. Krempler A, Qi Y, Triplett AA, Zhu J, Rui H, Wagner $\mathrm{KU}$. Generation of a conditional knockout allele for the Janus kinase 2 (Jak2) gene in mice. Genesis. 2004;40(1):52-57.

43. Møller N, Gjedsted J, Gormsen L, Fuglsang J, Djurhuus C. Effects of growth hormone on lipid metabolism in humans. Growth Horm IGF Res. 2003; 13(suppl A):S18-S21.

44. Fain JN, Ihle JH, Bahouth SW. Stimulation of lipolysis but not of leptin release by growth hormone is abolished in adipose tissue from Stat $5 \mathrm{a}$ and $\mathrm{b}$ knockout mice. Biochem Biophys Res Commun. 1999; 263(1):201-205.

45. Chawla A, Barak Y, Nagy L, Liao D, Tontonoz P, Evans RM. PPAR-gamma dependent and independent effects on macrophage-gene expression in lipid metabolism and inflammation. Nat Med. 2001; $7(1): 48-52$.

46. Zhou Y-C, Waxman DJ. STAT5b Down-regulates peroxisome proliferator-activated receptor $\alpha$ transcription by inhibition of ligand-independent activation function region-1trans-activation domain. J Biol Chem. 1999;274(42):29874-29882.

47. Postic C, Magnuson MA. DNA excision in liver by an albumin-Cre transgene occurs progressively with age. Genesis. 2000;26(2):149-150.

48. Sakharova AA, et al. Role of growth hormone in regulating lipolysis, proteolysis, and hepatic glucose production during fasting. J Clin Endocrinol Metab. 2008;93(7):2755-2759.

49. Jansson JO, Downs TR, Beamer WG, Frohman LA. Receptor-associated resistance to growth hormone-releasing factor in dwarf "little" mice. Science. 1986;232(4749):511-512.

50. Takahashi S, Satozawa N. The $20-\mathrm{kD}$ human growth hormone reduces body fat by increasing lipolysis and decreasing lipoprotein lipase activity. Horm Res. 2002;58(4):157-164.

51. Nguyen P, et al. Liver lipid metabolism. J Anim Physiol Anim Nutr (Berl). 2008;92(3):272-283.

52. Cheung L, et al. Hormonal and nutritional regulation of alternative CD36 transcripts in rat liver - a role for growth hormone in alternative exon usage. BMC Mol Biol. 2007;8:60.

53. Memon RA, Fuller J, Moser AH, Smith PJ, Grunfeld C, Feingold KR. Regulation of putative fatty acid transporters and Acyl-CoA synthetase in liver and adipose tissue in ob/ob mice. Diabetes. 1999;48(1):121-127.

54. Knutson SK, Chyla BJ, Amann JM, Bhaskara S, Huppert SS, Hiebert SW. Liver-specific deletion of histone deacetylase 3 disrupts metabolic transcriptional networks. EMBOJ. 2008;27(7):1017-1028.

55. Hosui A, Kimura A, Yamaji D, Zhu BM, Na R, Hennighausen L. Loss of STAT5 causes liver fibrosis and cancer development through increased TGF\{beta\} and STAT3 activation. J Exp Med. 2009; 206(4):819-831.

56. Uotani S, Abe T, Yamaguchi Y. Leptin activates AMP-activated protein kinase in hepatic cells via a JAK2-dependent pathway. Biochem Biophys Res Comm. 2006;351(1):171-175.

57. Keller U, Miles JM. Growth hormone and lipids. Horm Res. 1991;36(suppl 1):36-40.
58. Berryman DE, et al. Two-year body composition analyses of long-lived GHR null mice. J Gerontol A Biol Sci Med Sci. 2010;65(1):31-40.

59. Bartke A, Chandrashekar V, Bailey B, Zaczek D, Turyn D. Consequences of growth hormone (GH) overexpression and GH resistance. Neuropeptides. 2002;36(2-3):201-208.

60. Attie AD, et al. Relationship between stearoyl-CoA desaturase activity and plasma triglycerides in human and mouse hypertriglyceridemia. J Lipid Res. 2002;43(11):1899-1907.

61. Kotronen A, et al. Hepatic stearoyl-CoA desaturase (SCD)- 1 activity and diacylglycerol but not ceramide concentrations are increased in the nonalcoholic human fatty liver. Diabetes. 2009;58(1):203-208.

62. Stahl A, Gimeno RE, Tartaglia LA, Lodish HF. Fatty acid transport proteins: a current view of a growing family. Trends Endocrinol Metab. 2001;12(6):266-273.

63. Bonen A, et al. Regulation of fatty acid transport by fatty acid translocase/CD36. Proc Nutr Soc. 2004; 63(2):245-249.

64. Ibrahimi A, et al. Muscle-specific overexpression of FAT/CD36 enhances fatty acid oxidation by contracting muscle, reduces plasma triglycerides and fatty acids, and increases plasma glucose and insulin. J Biol Chem. 1999;274(38):26761-26766.

65. Zhou J, et al. Hepatic fatty acid transporter Cd36 is a common target of LXR, PXR, and PPAR [gamma] in promoting steatosis. Gastroenterology. 2008; 134(2):556-567.e551.

66. Tontonoz P, Nagy L, Alvarez JGA, Thomazy VA, Evans RM. PPAR[gamma] promotes monocyte/ macrophage differentiation and uptake of oxidized LDL. Cell. 1998;93(2):241-252.

67. Gan SK, Watts GF. Is adipose tissue lipolysis always an adaptive response to starvation? implications for non-alcoholic fatty liver disease. Clin Sci (London). 2008;114(8):543-545.

68. Postic C, et al. Dual roles for glucokinase in glucose homeostasis as determined by liver and pancreatic beta cell-specific gene knock-outs using Cre recombinase. J Biol Chem. 1999;274(1):305-315.

69. Dolganov GM, et al. A novel method of gene transcript profiling in airway biopsy homogenates reveals increased expression of a $\mathrm{Na}+-\mathrm{K}+-\mathrm{Cl}-$ cotransporter (NKCC1) in asthmatic subjects. Genome Res. 2001;11(9):1473-1483.

70. Kane JP, Malloy MJ, Ports TA, Phillips NR, Diehl JC, Havel RJ. Regression of coronary atherosclerosis during treatment of familial hypercholesterolemia with combined drug regimens. JAMA. 1990;264(23):3007-3012.

71. Warnick GR, Benderson J, Albers JJ. Dextran sulfate- $\mathrm{Mg} 2+$ precipitation procedure for quantitation of high-density-lipoprotein cholesterol. Clin Chem. 1982;28(6):1379-1388.

72. Friedewald WT, Levy RI, Fredrickson DS. Estimation of the concentration of low-density lipoprotein cholesterol in plasma, without use of the preparative ultracentrifuge. Clin Chem. 1972;18(6):499-502.

73. Bederman IR, Foy S, Chandramouli V, Alexander JC, Previs SF. Triglyceride synthesis in epididymal adipose tissue: contribution of glucose and non-glucose carbon sources. J Biol Chem. 2009;284(10):6101-6108.

74. Lee WN, et al. Measurement of fractional lipid synthesis using deuterated water $(2 \mathrm{H} 2 \mathrm{O})$ and mass isotopomer analysis. Am J Physiol. 1994; 266(3 pt 1):E372-E383.

75. Diraison F, Pachiaudi C, Beylot M. Measuring lipogenesis and cholesterol synthesis in humans with deuterated water: use of simple gas chromatographic/mass spectrometric techniques. J Mass Spectrom. 1997;32(1):81-86 